\title{
Spawns Structure of Rod-Like ZnO Wrapped in Cellulose Nanofibers for Electromagnetic Wave Absorption
}

\author{
Bitao Fan, ${ }^{1}$ Qiufang Yao, ${ }^{1}$ Chao Wang, ${ }^{1}$ Ye Xiong, ${ }^{1}$ Qingfeng Sun, ${ }^{1,2}$ and Chunde Jin ${ }^{1,2}$ \\ ${ }^{1}$ School of Engineering, Zhejiang A\&F University, Hangzhou, China \\ ${ }^{2}$ Key Laboratory of Wood Science and Technology, Hangzhou, China \\ Correspondence should be addressed to Qingfeng Sun; qfsun@zafu.edu.cn
}

Received 20 December 2016; Revised 26 February 2017; Accepted 21 March 2017; Published 27 April 2017

Academic Editor: Weilu Gao

Copyright (c) 2017 Bitao Fan et al. This is an open access article distributed under the Creative Commons Attribution License, which permits unrestricted use, distribution, and reproduction in any medium, provided the original work is properly cited.

\begin{abstract}
Spawns structure of rod-like $\mathrm{ZnO}$ wrapped in the cellulose nanofibers was successfully fabricated through a facile one-step hydrothermal method, and their electromagnetic wave absorption properties were investigated. The structure and properties of the composite aerogel were characterized. The enlarged morphology images showed that the as-prepared cellulose nanofiber/ZnO samples were spawns structure of rod-like $\mathrm{ZnO}$ wrapped in the cellulose nanofibers. The composite aerogel in a wax matrix exhibited excellent electromagnetic wave absorption performance over $2-18 \mathrm{GHz}$. The widest absorption bandwidth of $30 \mathrm{wt} \%$ contained with reflection loss values less than $-10 \mathrm{~dB}$ was up to $12 \mathrm{GHz}(6-18 \mathrm{GHz})$ at the thickness of $5.5 \mathrm{~mm}$ and the minimum reflection loss value reached $-26.32 \mathrm{~dB}$ at $15.2 \mathrm{GHz}$ when the thickness of the absorber was $3 \mathrm{~mm}$.
\end{abstract}

\section{Introduction}

The nanosized metal oxides are becoming very potential materials due to their physicochemical properties and various applications in different fields [1, 2]. Among oxide metals, zinc oxide $(\mathrm{ZnO})$ nanoparticle has attracted more attention because the zinc oxide nanoparticle is a promising material for applications in sensors, magnetics, electronics, and photocatalysis. In the past decade, $\mathrm{ZnO}$-based materials had been focused on for a candidate for electromagnetic (EM) wave absorption due to their excellent dielectric properties $[3,4]$, semiconductive properties [5], selectable mechanical properties [6] for a typical structural absorber, and large-scale synthesis $[7,8]$.

The research of inorganic nanoparticles/polymer composite was a very interesting materials, which could combine the properties of organic and inorganic materials $[9,10]$. On the other hand, the inorganic nanoparticles/polymer composite could improve the stability, retain the special morphology, and control the synthesis of nanoparticles [11]. Nanometer-sized single cellulose, the natural polymer, had been extensively used in kinds of fields due to its nanoscale dimensions [12], high surface area [13], unique morphology [14], low density [15], and high mechanical strength [16] with the entanglement of high-aspect-ratio [17] cellulose nanofibers (CNF).

In this study, the spawns structure of rod-like $\mathrm{ZnO}$ wrapped in CNF was successfully fabricated for EM wave absorption. In the system of the CNF/ZnO (CNFZ) composite, cellulose nanofibers were used as a scaffold. Combining cellulose and $\mathrm{ZnO}$ rods into the spawns structure could be considered as an effective and competitive route to obtain lightweight composites with outstanding EM wave absorbing performance.

\section{Material and Methods}

2.1. Materials. Zinc nitrate hexahydrate $\left(\mathrm{Zn}\left(\mathrm{NO}_{3}\right)_{2} \cdot 6 \mathrm{H}_{2} \mathrm{O}\right)$, hexamethylene tetramine $\left(\mathrm{C}_{6} \mathrm{H}_{14} \mathrm{~N}_{4}\right)$, and other chemicals were of analytical grade and were produced by Aladdin Industrial Co. The bamboo was obtained from the bamboo forest in Zhejiang, China. All the chemicals were used as received. Deionized water was used in all experiments.

2.2. Preparation of CNF. The purified cellulose after ultrasonic treatment was obtained; refer to Xie et al. [18]. Then the CNF colloid solution was obtained from the suspension 
after centrifugation at $6000 \mathrm{rpm}$ for 5 minutes. CNF colloid solution was separated into molds and placed in a refrigerator for about $12 \mathrm{~h}$. The frozen samples were freeze-dried for $60 \mathrm{~h}$ using a Scientz-18N freeze-dryer to sublime the materials. The cold trap temperature was less than $-55^{\circ} \mathrm{C}$, and the vacuum pressure was less than $10 \mu \mathrm{Pa}$ during the freeze-drying process. The sponge-like CNF was successfully prepared.

\subsection{Preparation of the CNFZ Composite Aerogel. The spawns} structure of rod-like $\mathrm{ZnO}$ wrapped in $\mathrm{CNF}$ was prepared by one-step hydrothermal approach [19]. $100 \mathrm{mg}$ CNF, $3 \mathrm{mmol}$ $\mathrm{Zn}\left(\mathrm{NO}_{3}\right)_{2} \cdot 6 \mathrm{H}_{2} \mathrm{O}$, and $3 \mathrm{mmol} \mathrm{C}{ }_{6} \mathrm{H}_{14} \mathrm{~N}_{4}$ were put into deionized water $(100 \mathrm{~mL})$ with magnetic stirring for $10 \mathrm{~min}$ at room temperature. Subsequently, the mixtures were transferred to a Teflon-lined stainless-steel autoclave. The autoclave was placed in an oven and heated at $100^{\circ} \mathrm{C}$ for $120 \mathrm{~min}$. After the suspension was cooled down naturally, the obtained homogeneous suspension was freeze-dried at $-55^{\circ} \mathrm{C}$ at $10 \mu \mathrm{Pa}$ for $60 \mathrm{~h}$. The lightweight, solid, and sponge-like CNFZ aerogel was successfully fabricated.

2.4. Characterization. The morphological feature of the CNF and CNFZ was observed using scanning electron microscope (SEM, FEI, Quanta 200, USA) and transmission electron microscope (TEM, FEI, Tecnai G20, USA). Crystalline structures were identified by X-ray diffraction technique (XRD, Rigaku, D/MAX 2200, Japan) operating with $\mathrm{Cu} \mathrm{K} \alpha$ radiation $(\lambda=1.5418 \AA)$ at a scan rate $(2 \theta)$ of $4^{\circ} \mathrm{min}^{-1}$ and the accelerating voltage of $40 \mathrm{kV}$ and the applied current of $30 \mathrm{~mA}$ ranging from $5^{\circ}$ to $75^{\circ}$. The $\mathrm{X}$-ray photoelectron spectroscopy (XPS, ULVAC-PHI, Inc., Japan) analysis of the specimen was carried out using a microfocused $(100 \mathrm{~lm}, 25 \mathrm{~W}, 15 \mathrm{kV})$ monochromatic Al-Ka source $(\mathrm{hm}=1486.6 \mathrm{eV})$, a hemispherical analyzer, and a multichannel detector. The composite samples used for EM wave absorption measurement were prepared by mixing the aerogel with paraffin wax $30 \mathrm{wt} \%$ of the aerogel. The EM wave absorption of the mixtures at 2-18 GHz frequency range was measured by using an Agilent E8363B vector network analyzer.

\section{Results and Discussion}

Figure 1 showed the morphological features of CNF and CNFZ. As shown in Figure 1(a), it could be observed that the slender fibers were cross-linked with a length of $150 \mu \mathrm{m}$. Figure 1(b) showed TEM image of CNF, which exhibited some slender fibrils with average diameter of $56.3 \mathrm{~nm}$. It could be concluded that the CNF had a large length-diameter ratio of about 2664. Figure 1(c) showed the SEM image of CNFZ. After the hydrothermal reaction, spawns structure of $\mathrm{ZnO}$ rods wrapped in the CNF was formed. Figure 1(d) showed the enlarged image of the spawns structure. Figure 1(e) showed the selected-area electron diffraction (SAED) pattern of CNFZ which indicated that a single rod was a single crystal. HRTEM image was shown in Figure 1(f). It was clearly revealed that lattice fringe with a spacing value of $0.28 \mathrm{~nm}$ depicts the lattice-resolved (100) crystalline plane of hexagonal $\mathrm{ZnO}$.
Figure 2 showed the XRD patterns of the CNF and CNFZ. As shown in Figure 2(a), it was clear that the diffraction peaks in XRD pattern at $2 \theta=16.5^{\circ}$ and $22.5^{\circ}$ were typical cellulose structure. In the case of CNFZ, the peaks of cellulose still exist in Figure 2(b), revealing that the crystal structure of cellulose did not change after the hydrothermal treatment. Furthermore, the additional diffraction peaks of CNFZ were observed at $31.75^{\circ}, 34.5^{\circ}, 36.3^{\circ}, 47.5^{\circ}, 56.6^{\circ}, 62.9^{\circ}, 66.4^{\circ}, 68.0^{\circ}$, and $69.1^{\circ}$ corresponding to the planes of (100), (002), (101), (102), (110), (103), (200), (112), and (201), which could be indexed to the hexagonal $\mathrm{ZnO}$ (wurtzite, JCPDS Number 361451).

Figure 3 showed the XPS spectra of the CNF and CNFZ. As shown in Figure 3(a), the wide scan spectra of the CNF exhibited two major peaks with binding energy at $286.1 \mathrm{eV}$ and $532.1 \mathrm{eV}$ corresponding to the $\mathrm{C} 1 \mathrm{~s}$ and $\mathrm{O}$ 1s of CNF, respectively. However, in the CNFZ, it exhibited four major peaks with binding energy at $286.1 \mathrm{eV}, 532.1 \mathrm{eV}, 1021.4 \mathrm{eV}$, and $1044.4 \mathrm{eV}$ corresponding to the $\mathrm{C} 1 \mathrm{~s}(286.1 \mathrm{eV}), \mathrm{O} 1 \mathrm{~s}$ $(532.1 \mathrm{eV})$, and $\mathrm{Zn} 2 \mathrm{p}(1021.4 \mathrm{eV}$ and $1044.4 \mathrm{eV})$ of CNFZ, respectively, which could indicate that the $\mathrm{Zn}$ element was added in the sample of CNFZ. The high-resolution XPS spectra of key elements ( $\mathrm{C} 1 \mathrm{~s}$ and $\mathrm{O}$ 1s) and extra element $(\mathrm{Zn}$ $2 \mathrm{p}$ ) were carried out and were shown in Figures 3(b)-3(f). As shown in Figure 3(b), the binding energies of $\mathrm{Zn}$ appeared at $1021.37 \mathrm{eV}$ and $1044.47 \mathrm{eV}$ (Figure 3(b)), respectively, which could be well attributed to the $\mathrm{Zn}$ element. It could be concluded that $\mathrm{ZnO}$ has been produced in CNFZ successfully. Figure 3(c) showed three peaks observed at $284.9 \mathrm{eV}, 286.3 \mathrm{eV}$, and $287.9 \mathrm{eV}$ in the high-resolution spectra of $\mathrm{C} 1 \mathrm{~s}$ in $\mathrm{CNF}$, which clearly indicated the presence of C-C, C-O, and O$\mathrm{C}-\mathrm{O}$. Upon hydrothermal reaction, the high-resolution $\mathrm{C}$ 1s spectrum of CNFZ (Figure 3(d)) showed similar results to those of CNF. The same peaks were located in the same places. The differences in the same peak on intensity at $284.9 \mathrm{eV}$ were attributed to $\mathrm{C}$-C; the results might be attributed to some degradation during hydrothermal treatment. Two peaks which attributed to $\mathrm{O}-\mathrm{H}$ and $\mathrm{O}-\mathrm{C}-\mathrm{O}$ and $\mathrm{C}-\mathrm{O}-\mathrm{C}$ were observed at $532.8 \mathrm{eV}$ in the high-resolution spectra of $\mathrm{O} 1 \mathrm{~s}$ in $\mathrm{CNF}$ (Figure 3(e)). Another peak was observed at $530.12 \mathrm{eV}$ in the high-resolution spectra of $\mathrm{O} 1 \mathrm{~s}$ in $\mathrm{CNFZ}$ except the two peaks in the high-resolution spectra of $\mathrm{O}$ 1s in CNF at the same location (Figure 3(f)). The additional peak could be attributed to the original lattice oxygen species in $\mathrm{ZnO}$ [20]. According to the above results, it could be deduced that $\mathrm{ZnO}$ would have been produced in CNFZ successfully.

Figure 4 showed the formation mechanism of the spawns structure of rod-like $\mathrm{ZnO}$ wrapped in CNF. A possible mechanism could be inferred from the basic physics of electrostatic interaction between positively charged $\mathrm{ZnO}$ and negatively charged CNF. Firstly, spawns structure of $\mathrm{ZnO}$ wrapped in CNF was prepared by a hydrothermal method. When $\mathrm{C}_{6} \mathrm{H}_{14} \mathrm{~N}_{4}$ and $\mathrm{Zn}\left(\mathrm{NO}_{3}\right)_{2}$ were added in cellulose nanofibers solution at $100^{\circ} \mathrm{C}$ for $120 \mathrm{~min}, \mathrm{ZnO}$ crystal seed was proceeding and homogeneously distributed in the solution. With the $\mathrm{ZnO}$ rods growing, spawns structure of rodlike $\mathrm{ZnO}$ wrapped in $\mathrm{CNF}$ was created by an electrostatic interaction between positively charged $\mathrm{ZnO}$ and negatively charged CNF. Therefore, CNF could be close to $\mathrm{ZnO}$ rods and 


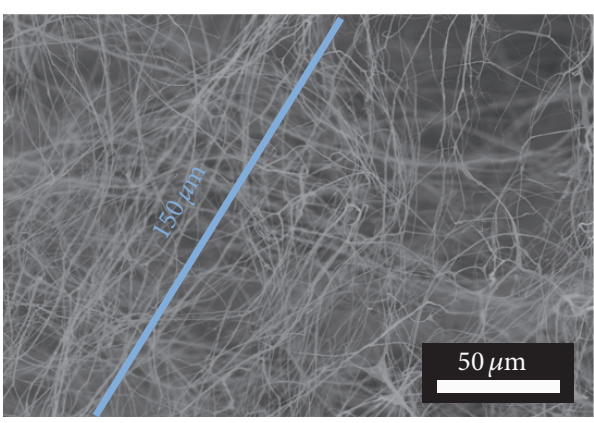

(a)

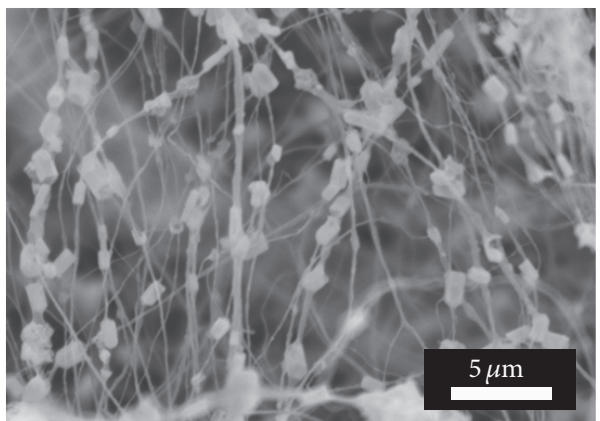

(c)

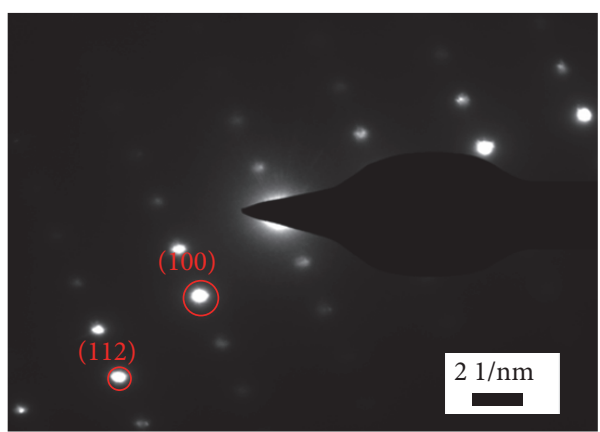

(e)

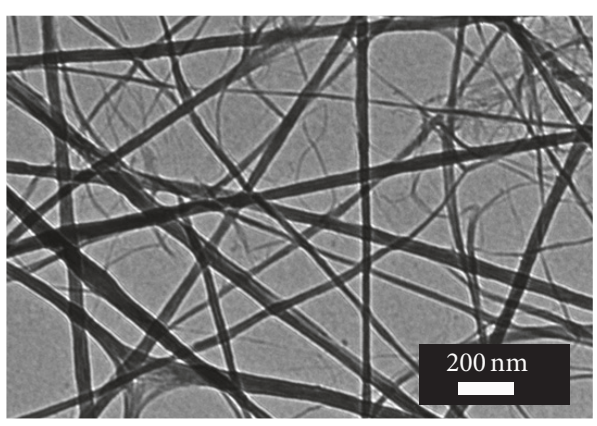

(b)

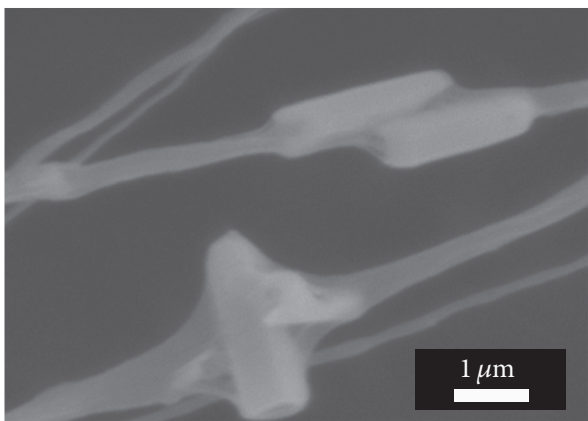

(d)

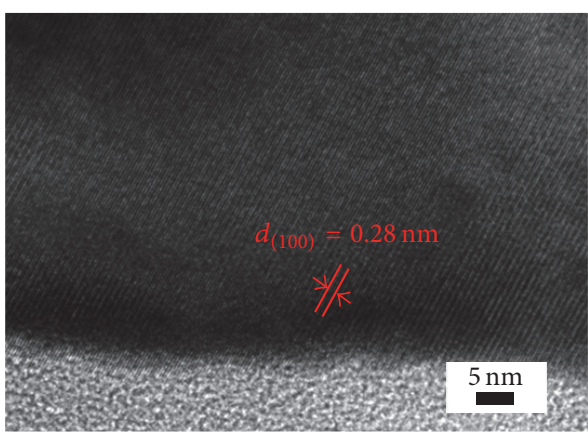

(f)

FIgure 1: The morphology of CNF and CNFZ. (a) The SEM and (b) TEM image of CNF, (c) the SEM, (d) the enlarged image, (e) HRTEM, and (f) SADE of CNFZ.

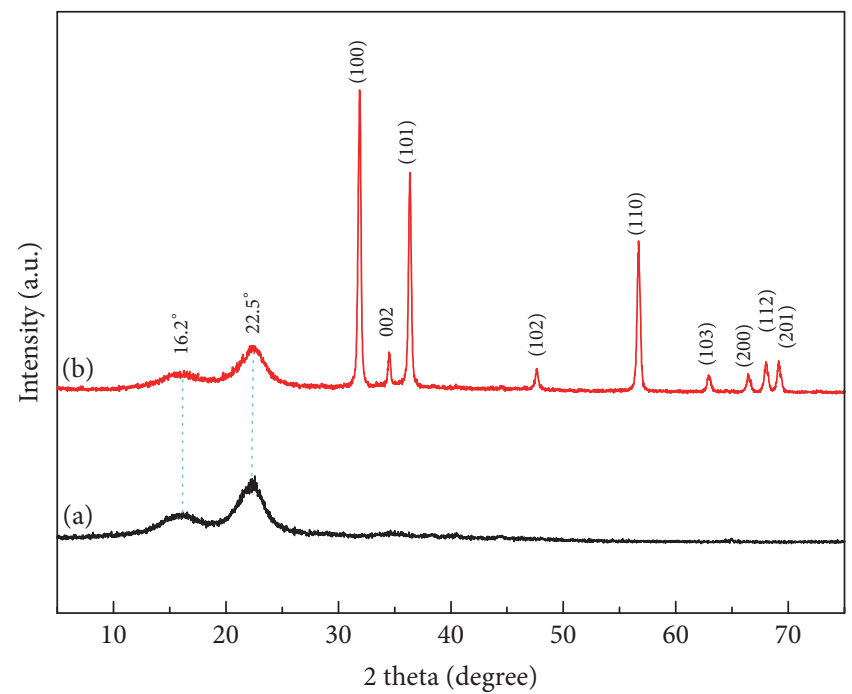

FIGURE 2: XRD patterns of (a) CNF and (b) CNFZ. 


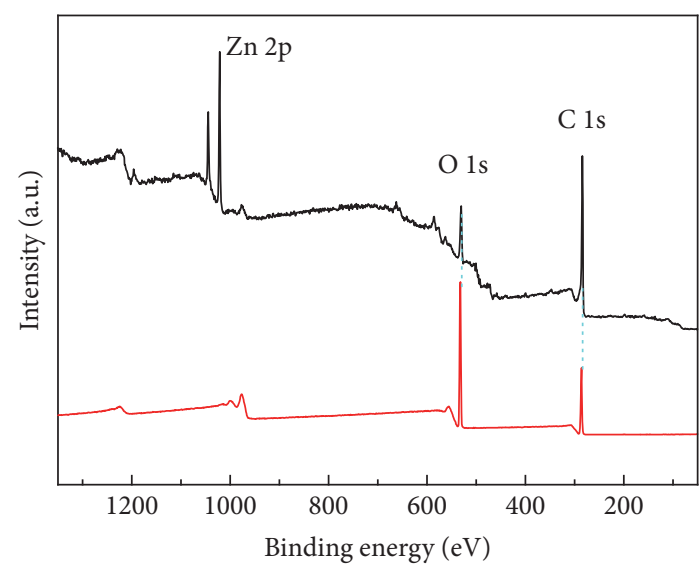

(a)

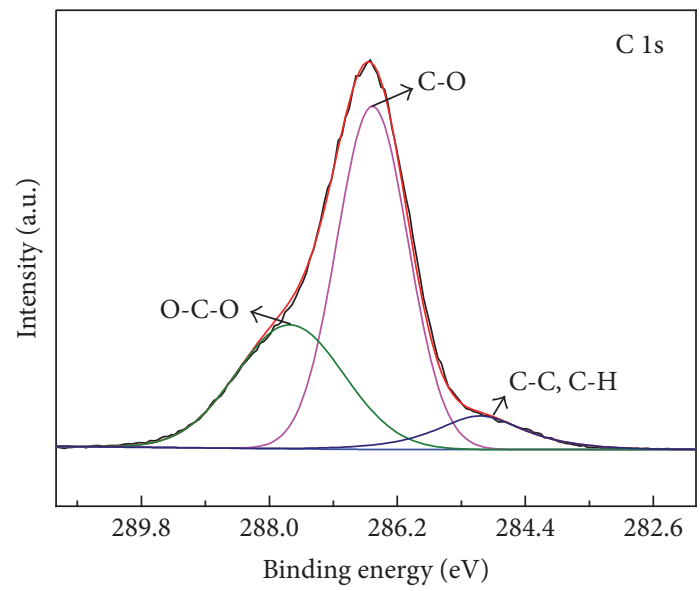

(c)

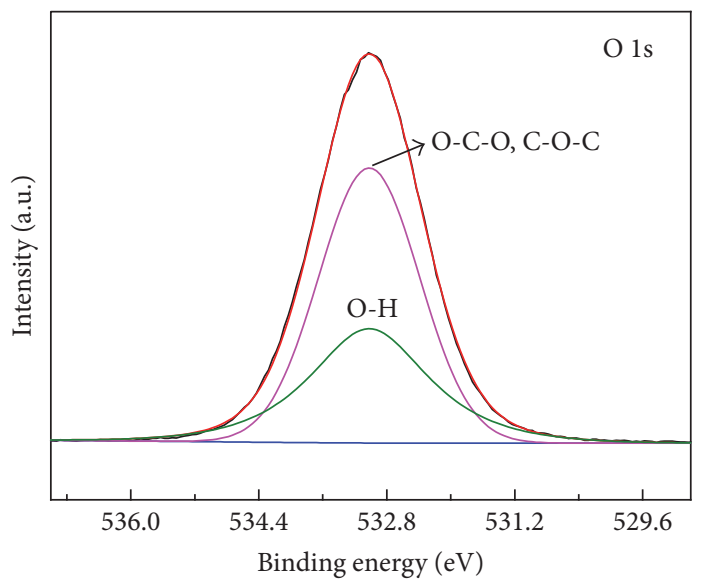

(e)

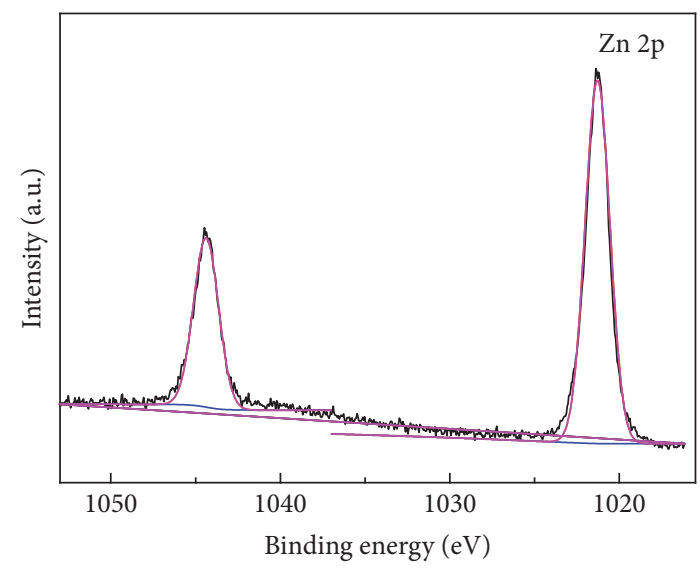

(b)

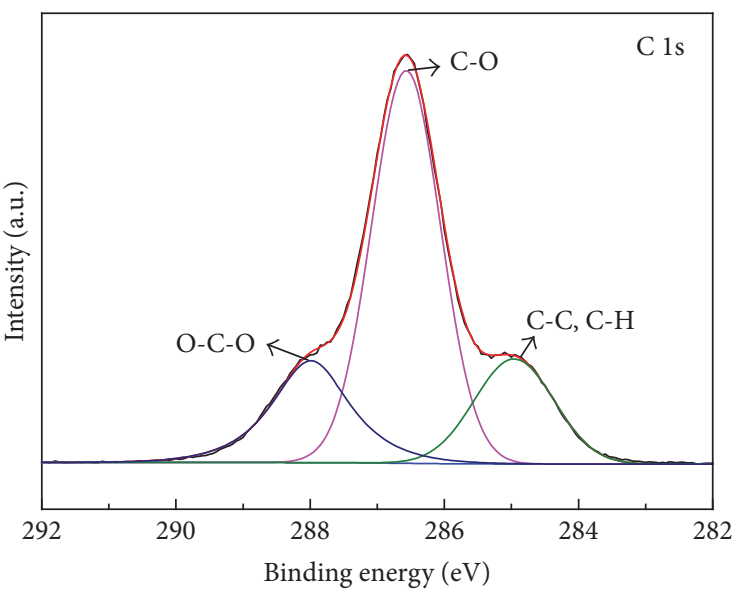

(d)

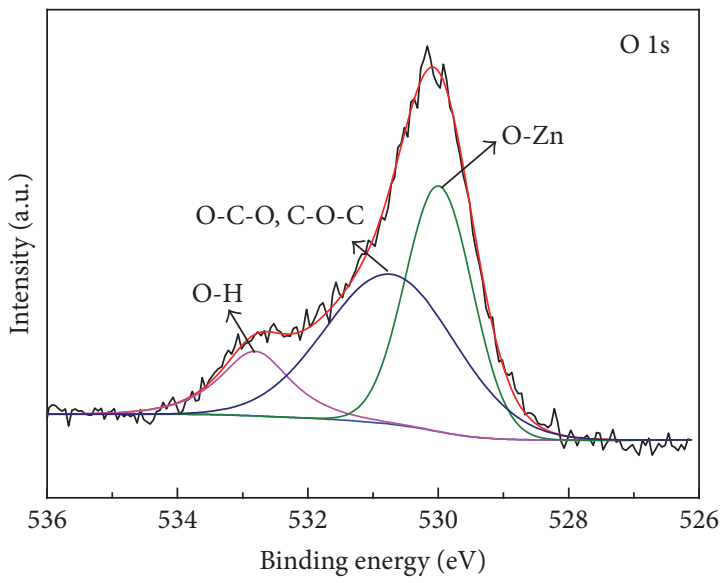

(f)

FIGURe 3: (a) A full scan XPS spectra of CNF and CNFT, (b) high-resolution XPS spectra of Zn element on CNFZ composite aerogel, (c and d) high-resolution XPS spectra of C 1s of CNF and CNFZ, and (e and f) high-resolution XPS spectra of O 1s of CNF and CNFZ.

wrapped $\mathrm{ZnO}$ rods like a net acted as a shell. Subsequently, freeze-drying was carried out to sublimate the liquid into gas phase. The lightweight aerogel with the structure of $\mathrm{ZnO}$ spawns wrapped in cellulose nanofibers was fabricated.

Figure 5 showed the reflection loss (RL) values versus frequency of the CNFZ at different thickness $(1-5.5 \mathrm{~mm})$ with a filler loading of $30 \mathrm{wt} \%$. It could be observed that the CNFZ exhibited a certain degree of abilities for EM wave absorption. The different thickness of the CNFZ had a great influence on the frequency of electromagnetism wave absorption properties. When the thickness increased, the frequency of RL peak had a tendency to shift from 


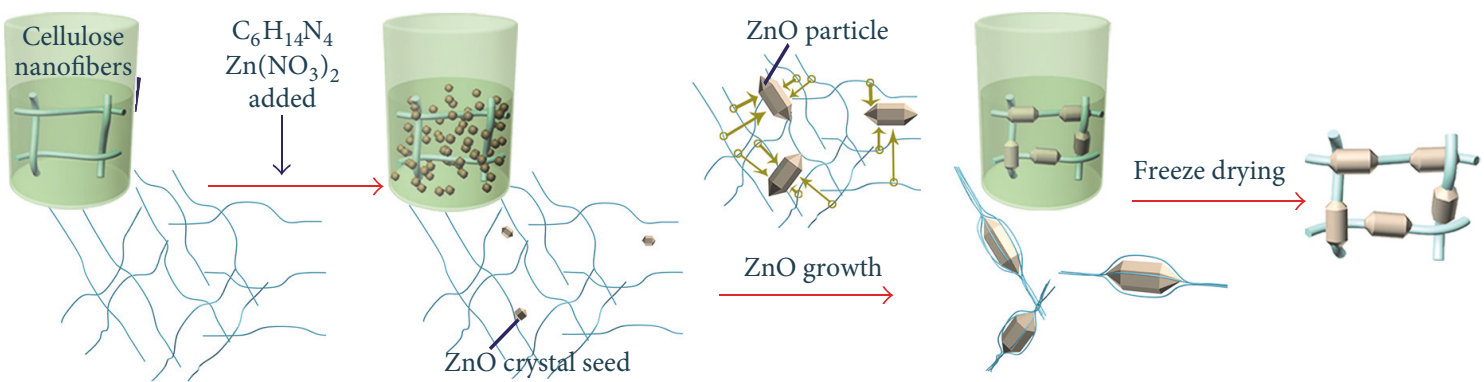

FIGURE 4: Schematic illustration of the formation process of spawns of rod-like $\mathrm{ZnO}$ wrapped in cellulose nanofibers.

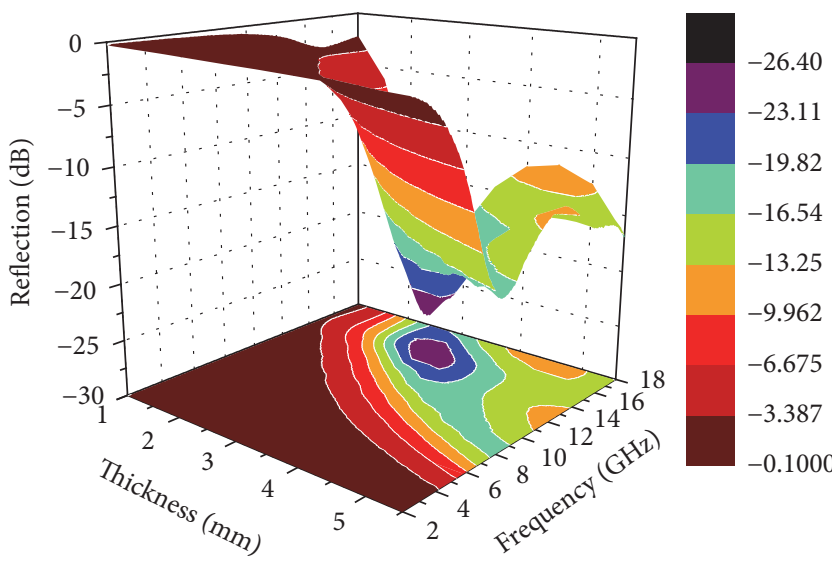

FIGURE 5: Reflection loss for the samples absorbers with loading of $30 \mathrm{wt} \%$ at different thickness.

high frequency to low frequency. The $\mathrm{RL}_{\min }$ value reached $-26.32 \mathrm{~dB}$ at $15.2 \mathrm{GHz}$ when the thickness of the absorber was $3 \mathrm{~mm}$. Importantly, the widest absorption bandwidth corresponding to $\mathrm{RL}$ value less than $-10 \mathrm{~dB}$ was almost up to $12 \mathrm{GHz}(6.0-18.0 \mathrm{GHz})$ at the thickness of $5.5 \mathrm{~mm}$. In order to increase the properties of absorption for EM, many researches had been conducted in the previous investigation. The summary of results for EM absorption employed by different structure of $\mathrm{ZnO}$ was shown in Table 1 . The $\mathrm{RL}$ behaviors of CNFZ usually depend on their loss mechanisms, which are determined by their nature and structure. The above results indicated that the spawns structure of rod-like $\mathrm{ZnO}$ wrapped in CNF had strong absorption for EM. This was mainly because of the interfacial electric polarization. It can be noticed that the spawns structure of rod-like $\mathrm{ZnO}$ wrapped in $\mathrm{CNF}$ had unique multiple interfaces between the rod-like $\mathrm{ZnO}, \mathrm{CNF}$, paraffin matrix, and air bubbles. It is available for the EM to penetrate the porous layer formed by the multiple poles at the interfaces and the energy will be induced into dissipative current, which leads to the energy attenuation.

\section{Conclusions}

Spawns structure of rod-like $\mathrm{ZnO}$ wrapped in CNF was successfully fabricated through a facile hydrothermal process. CNF could be close to $\mathrm{ZnO}$ rods and wrapped $\mathrm{ZnO}$ rods like spawns structure due to the basic physics of electrostatic
TABLE 1: Summary of results for EM absorption employed by different structure of $\mathrm{ZnO}$.

\begin{tabular}{|c|c|c|c|c|}
\hline Materials & Structure & $\begin{array}{l}\mathrm{RL}_{\min } \\
(\mathrm{dB})\end{array}$ & $\begin{array}{l}\text { Width }(\mathrm{GHz}) \\
\left(\mathrm{RL}_{\min } \leq 10\right)\end{array}$ & Ref \\
\hline $\mathrm{ZnO}$ & CNFZ & -26.32 & 12 & This work \\
\hline $\mathrm{ZnO}$ & $\begin{array}{l}\text { Urchin-like } \mathrm{ZnO} \\
\text { hollow spheres }\end{array}$ & -20 & 1.2 & [20] \\
\hline $\mathrm{ZnO}$ & $\begin{array}{c}\mathrm{Zn}(\mathrm{Fe}) / \mathrm{ZnO} \\
\text { nanocapsules }\end{array}$ & -18 & 8 & [21] \\
\hline $\mathrm{ZnO}$ & $\begin{array}{l}\text { Uniform } \mathrm{ZnO} \\
\text { nanorods }\end{array}$ & -25.44 & 3.8 & {$[22]$} \\
\hline $\mathrm{ZnO}$ & $\begin{array}{c}\text { Porous Fe3O4@ZnO } \\
\text { sphere }\end{array}$ & -37.5 & 11.4 & {$[23]$} \\
\hline
\end{tabular}

interaction between positively charged $\mathrm{ZnO}$ and negatively charged CNF. The composite aerogel in a wax matrix exhibits excellent EM wave absorption performance. The widest absorption bandwidth with RL values less than $-10 \mathrm{~dB}$ was up to $12 \mathrm{GHz}(6-18 \mathrm{GHz})$ and the minimum $\mathrm{RL}$ value reached $-26.32 \mathrm{~dB}$ at $15.2 \mathrm{GHz}$.

\section{Conflicts of Interest}

The authors declare that there are no conflicts of interest regarding the publication of this manuscript.

\section{Acknowledgments}

This work was supported by Zhejiang Provincial Natural Science Foundation of China (no. LZ14C160001), Scientific Research Foundation of Zhejiang A\&F University (Grant no. 2014FR077), Public Projects of Zhejiang Province (no. 2015C32014), and the Fund for Innovative Research Team of Forestry Engineering Discipline (101-206001000713).

\section{References}

[1] S. Alexander, V. Gomez, and A. R. Barron, "Carboxylation and decarboxylation of aluminum oxide nanoparticles using bifunctional carboxylic acids and octylamine," Journal of Nanomaterials, vol. 2016, Article ID 7950876, 2016.

[2] D.-Y. Kang, P. Pokharel, Y.-S. Kim, S. Choi, and S.-H. Choi, "Synthesis of metal oxide decorated polycarboxyphenyl polymer-grafted multiwalled carbon nanotube composites by 
a chemical grafting approach for supercapacitor application," Journal of Nanomaterials, vol. 2015, Article ID 535319, pp. 1-11, 2015.

[3] A. S. Lanje, S. J. Sharma, R. S. Ningthoujam, J.-S. Ahn, and R. B. Pode, "Low temperature dielectric studies of zinc oxide $(\mathrm{ZnO})$ nanoparticles prepared by precipitation method," Advanced Powder Technology, vol. 24, no. 1, pp. 331-335, 2013.

[4] Y.-H. Lin and J.-C. Chou, "Interface study on amorphous indium gallium zinc oxide thin film transistors using high-k gate dielectric materials," Journal of Nanomaterials, vol. 2015, Article ID 782786, pp. 1-6, 2015.

[5] J. Xu, Z. Chen, J. A. Zapien, C.-S. Lee, and W. Zhang, "Surface engineering of $\mathrm{ZnO}$ nanostructures for semiconductorsensitized solar cells," Advanced Materials, vol. 26, no. 31, pp. 5337-5367, 2014.

[6] J. Liu, W. Cao, H. Jin, J. Yuan, D. Zhang, and M. Cao, "Enhanced permittivity and multi-region microwave absorption of nanoneedle-like $\mathrm{ZnO}$ in the $\mathrm{X}$-band at elevated temperature," Journal of Materials ChemistryC, vol. 3, no. 18, pp. 46704677, 2015.

[7] S. S. Arbuj, N. Rumale, A. Pokle et al., "Synthesis of photoluminescent $\mathrm{ZnO}$ nanopencils and their photocatalytic performance," Science of Advanced Materials, vol. 6, no. 2, pp. 269-275, 2014.

[8] F. Davar, A. Majedi, and A. Mirzaei, "Green synthesis of $\mathrm{ZnO}$ nanoparticles and its application in the degradation of some dyes," Journal of the American Ceramic Society, vol. 98, no. 6, pp. 1739-1746, 2015.

[9] J. Zeng, S. Liu, J. Cai, and L. Zhang, " $\mathrm{TiO}_{2}$ immobilized in cellulose matrix for photocatalytic degradation of phenol under weak UV light irradiation," Journal of Physical Chemistry C, vol. 114, no. 17, pp. 7806-7811, 2010.

[10] T. Thorvaldsen, B. B. Johnsen, T. Olsen, and F. K. Hansen, "Investigation of theoretical models for the elastic stiffness of nanoparticle-modified polymer composites," Journal of Nanomaterials, vol. 2015, Article ID 281308, pp. 1-17, 2015.

[11] M. Fujita, N. Idota, K. Matsukawa, and Y. Sugahara, "Preparation of oleyl phosphate-modified $\mathrm{TiO}_{2} /$ poly(methyl methacrylate) hybrid thin films for investigation of their optical properties," Journal of Nanomaterials, vol. 2015, Article ID 297197, 2015.

[12] L. Berglund, M. Noël, Y. Aitomäki, T. Öman, and K. Oksman, "Production potential of cellulose nanofibers from industrial residues: efficiency and nanofiber characteristics," Industrial Crops and Products, vol. 92, pp. 84-92, 2016.

[13] C. Moser, G. Henriksson, and M. E. Lindström, "Specific surface area increase during cellulose nanofiber manufacturing related to energy input," BioResources, vol. 11, no. 3, pp. 7124-7132, 2016.

[14] H. Almasi, B. Ghanbarzadeh, J. Dehghannya, A. A. Entezami, and A. K. Asl, "Novel nanocomposites based on fatty acid modified cellulose nanofibers/poly(lactic acid): morphological and physical properties," Food Packaging and Shelf Life, vol. 5, pp. 21-31, 2015.

[15] Y. Jiao, C. Wan, T. Qiang, and J. Li, "Synthesis of superhydrophobic ultralight aerogels from nanofibrillated cellulose isolated from natural reed for high-performance adsorbents," Applied Physics A: Materials Science and Processing, vol. 122, pp. 1-10, 2016.

[16] W. Chen, Q. Li, J. Cao et al., "Revealing the structures of cellulose nanofiber bundles obtained by mechanical nanofibrillation via TEM observation," Carbohydrate Polymers, vol. 117, pp. 950956, 2015.
[17] N. Amiralian, P. K. Annamalai, P. Memmott, E. Taran, S. Schmidt, and D. J. Martin, "Easily deconstructed, high aspect ratio cellulose nanofibres from Triodia pungens; an abundant grass of Australia's arid zone," RSC Advances, vol. 5, no. 41, pp. 32124-32132, 2015.

[18] J. Xie, C.-Y. Hse, C. F. De Hoop, T. Hu, J. Qi, and T. F. Shupe, "Isolation and characterization of cellulose nanofibers from bamboo using microwave liquefaction combined with chemical treatment and ultrasonication," Carbohydrate Polymers, vol. 151, pp. 725-734, 2016.

[19] K. V. Gurav, M. G. Gang, S. W. Shin et al., "Gas sensing properties of hydrothermally grown $\mathrm{ZnO}$ nanorods with different aspect ratios," Sensors ande Actuators B: Chemical, vol. 190, no. 1, pp. 439-445, 2014.

[20] G. Wu, Y. Cheng, Q. Xie, Z. Jia, F. Xiang, and H. Wu, "Facile synthesis of urchin-like $\mathrm{ZnO}$ hollow spheres with enhanced electromagnetic wave absorption properties," Materials Letters, vol. 144, no. 1, pp. 157-160, 2015.

[21] Z. H. Wang, L. W. Jiang, D. Li et al., "Permittivity and permeability of $\mathrm{Zn}(\mathrm{Fe}) / \mathrm{ZnO}$ nanocapsules and their microwave absorption in the 2-18GHz range," Journal of Applied Physics, vol. 115, no. 17, 401 pages, 2014.

[22] G.-S. Wang, Y.-Y. Wu, X.-J. Zhang, Y. Li, L. Guo, and M.-S. Cao, "Controllable synthesis of uniform $\mathrm{ZnO}$ nanorods and their enhanced dielectric and absorption properties," Journal of Materials Chemistry A, vol. 2, no. 23, pp. 8644-8651, 2014.

[23] D. Sun, Q. Zou, Y. Wang, Y. Wang, W. Jiang, and F. Li, “Controllable synthesis of porous $\mathrm{Fe}_{3} \mathrm{O}_{4} @ \mathrm{ZnO}$ sphere decorated graphene for extraordinary electromagnetic wave absorption," Nanoscale, vol. 6, no. 12, pp. 6557-6562, 2014. 

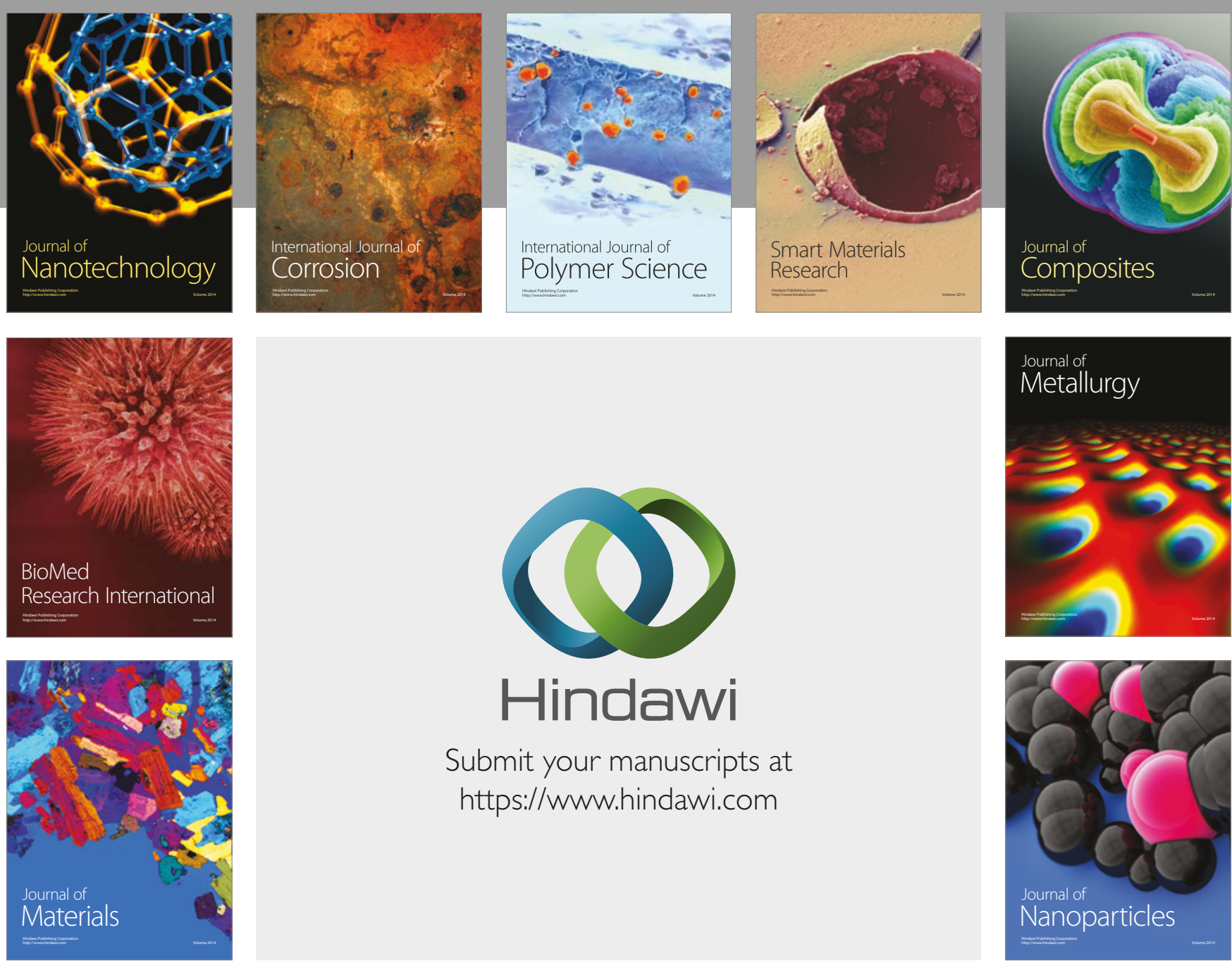

\section{Hindawi}

Submit your manuscripts at

https://www.hindawi.com
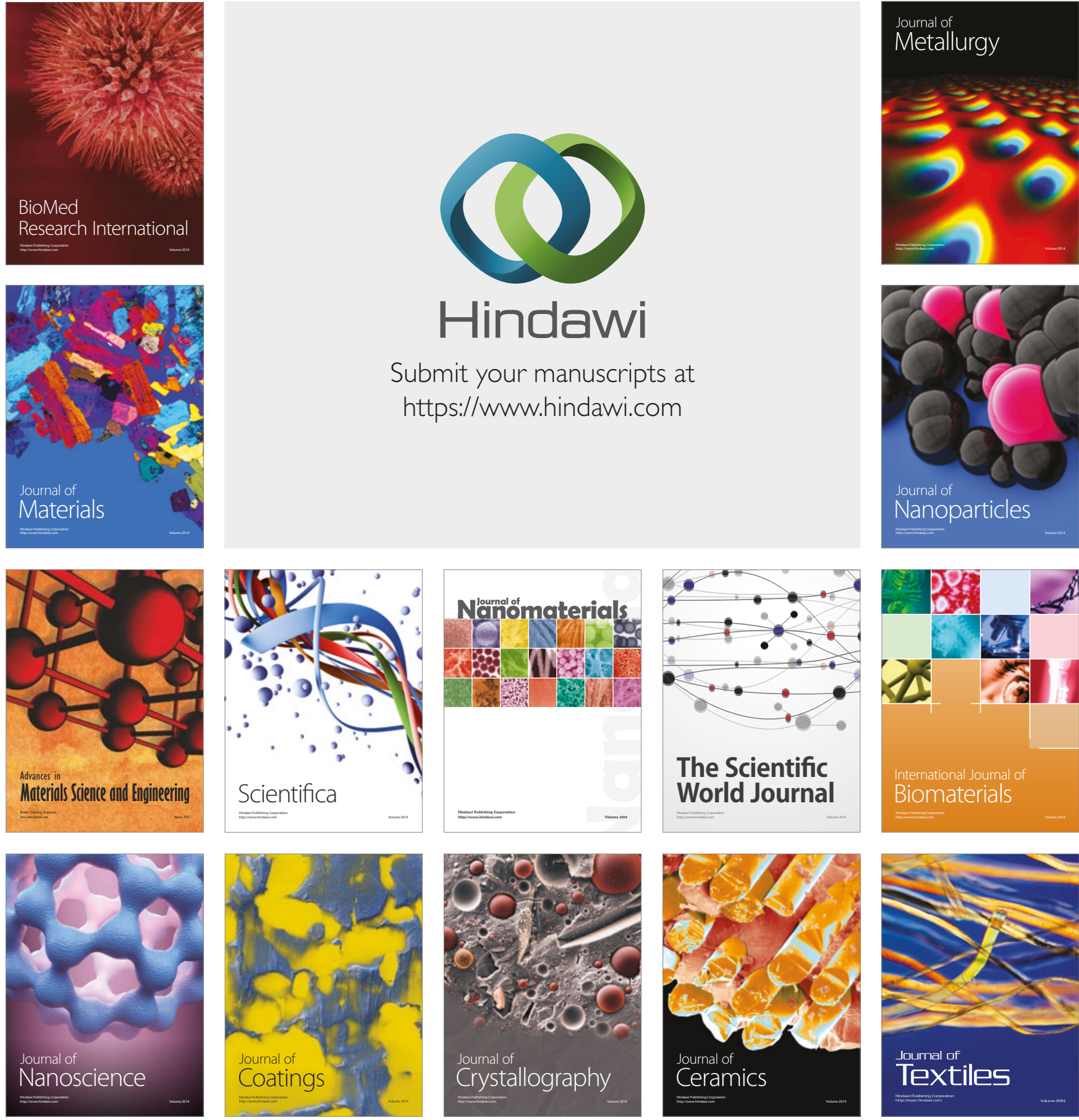

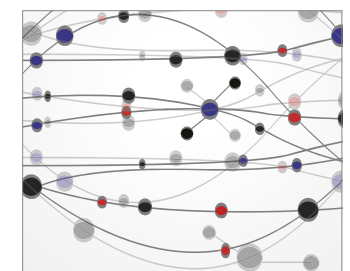

The Scientific World Journal
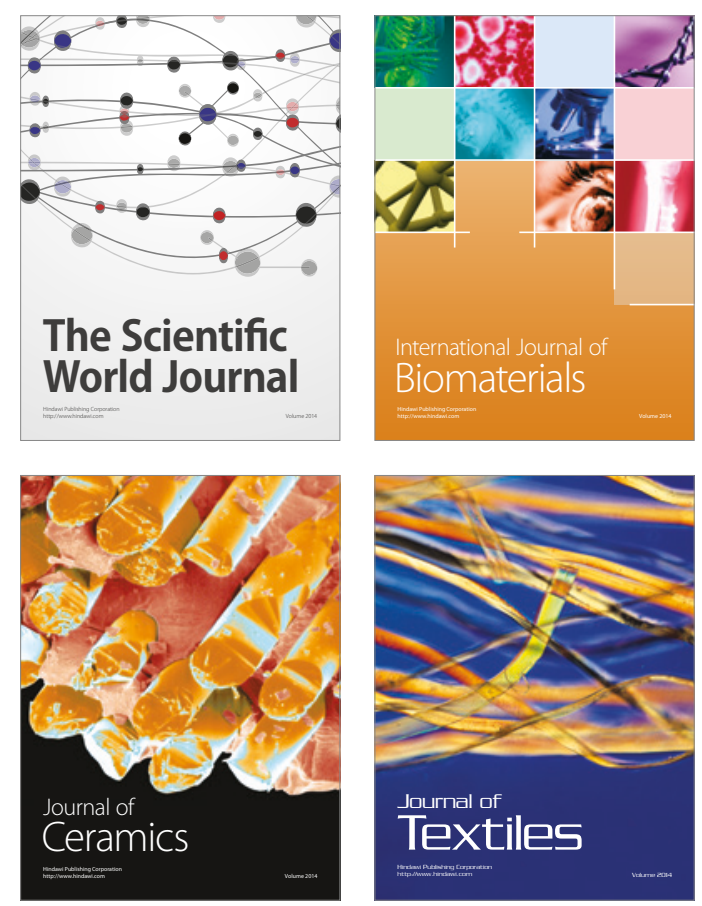